\title{
A STRUCTURED ANALYSIS OF CAAD EDUCATION
}

\section{Şule Taşlı Pektaş}

\begin{abstract}
After more than four decades of its beginnings, Computer Aided Architectural Design (CAAD) has already reached a level of maturity in both the education and the profession. There is an ever-growing amount of literature on the subject; however, relatively few studies have taken a systematic approach to analyze CAAD education. Moreover, design institutions often view CAAD merely as a technical issue ignoring socio-cultural and theoretical aspects. In order to alleviate these problems, this paper presents a structured analysis of CAAD education based on Prof. Necdet Teymur's theory of architectural education. Prof. Teymur claims that the components of architectural education should be studied in terms of objectives (why), contents (what), methodology (how) and management (who) along with four different knowledge and disciplinary levels (viewpoints); namely, sociological, ideological, epistemological, and pedagogical. In this paper, current issues of CAAD education are addressed within this framework and several proposals are presented.
\end{abstract}

Keywords: Computer Aided Architectural Design (CAAD) Education, Architectural Education Theory, Curriculum, Design Studio, Integration

\section{INTRODUCTION}

The impacts of information technologies on information-based fields tend to be profound and revolutionary. It was widely recognized that building design is an "information processing" activity after the pioneering work of Akin (1986). The principal requirement of any building design project is evalvating and processing information and communicating that information between the parties involved. Hence, the utilization of information technologies in architectural design, widely known as Computer Aided Architectural Design (CAAD), has the potential for affecting processes and products of the discipline as well as its education. There is a considerably large -and ever growing- body of literature on the subject; however, it is observed that few studies have used a systematic approach to discuss CAAD education. In order to alleviate the problem, this paper presents a structured analysis of CAAD education based on Prof. Necdet Teymur's system $(1997 ; 2001)$ for scrutinizing architectural education.

Teymur (2001) recognizes that architectural education has been handled as a "practice without theory." In order to elevate architectural education debates from the level of mere experience to that of structured, systematic and critical analysis, he rec-

- 46 ommends "problematization." When architectural education is defined as a "problem," it inevitably calls for theory. Teymur argues that such theories can not be directly borrowed from education discipline not only due to the lack of interest in professional education in that discipline, but also due to the peculiarities of architectural education. Aiming at a reconciliation of several concerns, he suggests that analyses of architectural education can be organized within the framework of four basic questions: objectives and motivations (why), contents (what), methodology and medium (how) and management and staff (who) and different knowledge and disciplinary perspectives; namely, sociological, ideological, epistemological, and pedagogical (Teymur, 1997; 2001). His theory is based on a simple set of concepts and questions that already exist in educational studies piecemeal (Lawton et al., 1978; Salama, 2006), however, as a whole it represents a unique and validated approach. The International Union of Architects (UIA) adopted Teymur's system as a framework for discussing issues related to architectural education (UIA, 2002). It was also applied in implementation of web-based design studios (Sagun et al., 2001).

The present study utilizes the theory as a tool to raise questions about the several aspects of CAAD education. Given the large body of the literature on 
the subject and the diversity of educational approaches to $C A A D$, providing a structured analysis of the current topics of CAAD education is a difficult endeavour. Therefore, only the most important considerations could be discussed under each title. Predictions about the future of CAAD education and suggestions for further research are also made in this paper.

\section{OBJECTIVES AND MOTIVATIONS}

The first step of analyzing CAAD education is to understand "why" it is important. We believe that the increasing importance of CAAD is largely due to the new possibilities and modes of design thinking that it brought to architectural design. Earlier conception of the use of computers in design was the vision of a tool which "assists" existing design processes (Mitchell, 1994). During the 1980s, computers have been increasingly used for drafting purposes, a design activity which is now almost completely computerized in architectural offices. If the role of computer in architectural design remained merely as a drafting tool, its effect on architectural education would not be much different than that of pencils and drawing papers. However, beginning from the 1990s, developments in CAAD opened up new perspectives and challenged existing processes. Due to new visualization software, forms once were difficult to imagine became easy to produce and the "virtual" established as a legitimate architectural object. The next important change was the implementation of network technologies which gave rise to CSCW (Computer Supported Collaborative Work) and e-commerce. CSCW enabled collaboration of geographically distributed design professionals and formation of "virtual teams" (Tasli, 1999: 28-33). All of these events have affected traditional architectural design practices, although the impact was less far-reaching compared to large industries such as aerospace and automotive. The reason for this is probably the peculiar characteristics of the building industry. The building industry is more fragmented, project-specific and culturally diverse compared to the other industries (Pektas and Pultar, 2006). These factors hindered transformation of conventional practices in some extent, however, the incremental change is still in progress.

Architectural education has also been a part of these developments and has devised its own means of approaching CAAD. During the last decade, computing has been included in the curriculum of almost every architectural school. Many researches are being done on the subject and the debate on CAAD education proliferates through conferences of organizations such as ECAADE (Education and Research in Computer Aided Architectural Design in Europe), ACADIA (Association for Computer Aided Design in Architecture) and CAADRIA (Association for Computer Aided Architectural Design Research in Asia). Due to the developments briefly summarized above, CAAD education deserves further inquiry. In the following sections of this paper, several aspects of different approaches to CAAD education are discussed according to the proposed framework.

\section{CONTENTS}

A key topic for CAAD education is the content. "What" should be taught as CAAD, the theories, the methods, or the skills? Is CAAD an essential part of architectural thinking or just another skill that can be sought for competitiveness in the job market? Two opposite ends can be defined with respect to this question. Some view CAAD simply as a skill (Novitski, 1999) and others advocate that CAAD teaching should be related to the theories of architecture and/or should develop its own "digital design theory" (Oxman, 2006). Because of the wide diversity of the approaches to CAAD, categorizing the domain of digital design is a difficult task and of course, many interesting approaches are somewhere in between.

The conception of CAAD as a skill has been promoted mostly by practitioners and pragmatists due to the fact that CAAD has already become a driving force for architectural market. In a recent survey, practicing Turkish architects were asked to identify the factors that have been most influential in architectural practice within the last ten years. Following the developments in construction materials, computer technologies ranked second in a 

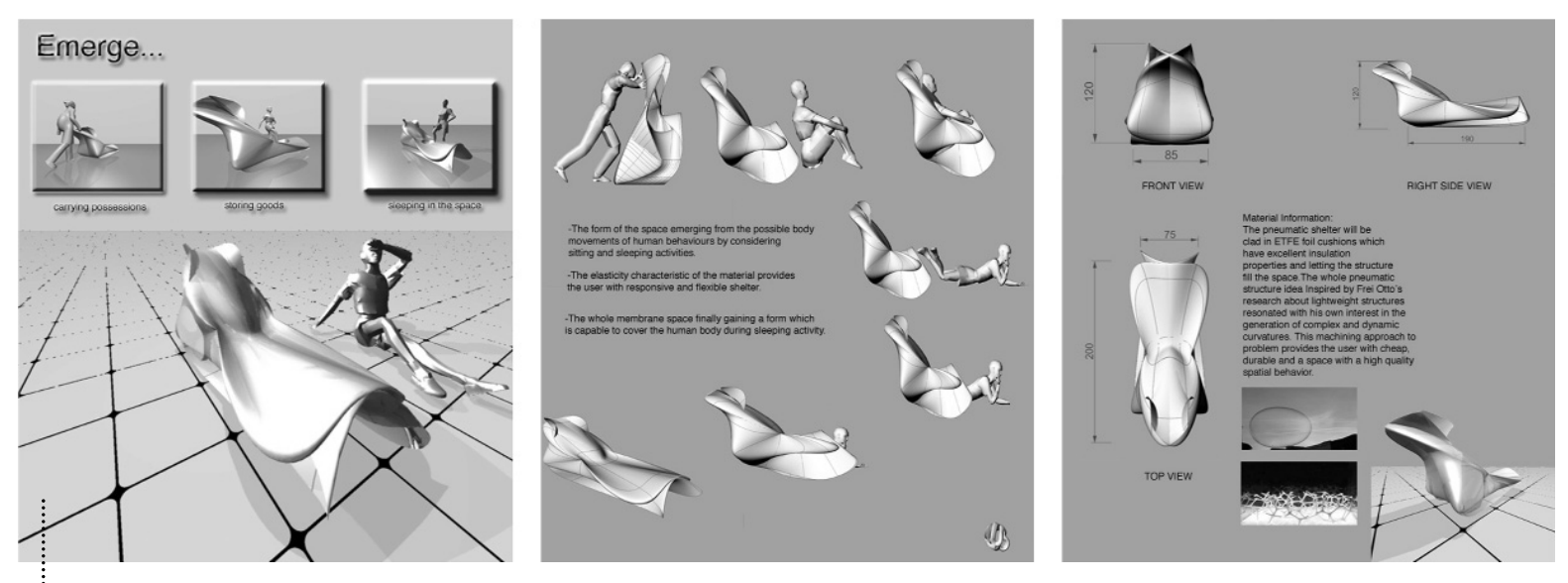

Fig 7. 3D modelling tools enable students to experiment with complex forms. "EMERGE" Participant for the international design competition entitled Designboom Social Awareness Award 2006, with the subject "Shelter in a Cart" for urban homeless. The figure shows a pneumatic structure with elastic material providing the user with a flexible shelter, not only for sitting and resting but also for sleeping, while the membrane finally covers the whole human body. (Designers: O. Ozkaya and O. Uludamar, Tutor: T. Sonkan)

number of factors. Moreover, the factors ranked third and fourth in the survey were also related to computers; namely, Internet and communication technologies and CAD technology (YEM, 2006). Under the demanding market conditions, architects seek for competence in the production of digital renderings, animations and construction documents while employing new graduates. Due to these developments and to the massive increase in architecture graduates, manual drafters with no architectural education have disappeared in recent years. They have been replaced by CAAD operators probably about half of whom are qualified architects (Stevens, 1997). Regarding these issues, schools are forced to shape the content of their CAAD curriculum to provide necessary skills and a competitive advantage for their graduates.

On the other hand, digital design is increasingly being conceived as a new form of design rather than merely conventional design conducted through digital media. The Non-Standard Architectures Exhibition at the Pompidou Centre in Paris (Migayrou and Mennan, 2003), catalyzed the emergence of the concept of non-standard and non-repetitive design as an antithesis of formal "complexity and contradiction" of post-modern architecture. Mitchell (2005) argues that the emerging architecture of the digital era is characterized by high levels of complexity which enables more sensitive and diverse response to the require- ments of contextual aspects such as site, program and expressive intention than was generally possible within the framework of industrial modernism. The concept of a "non-standard" architecture, with its performative qualities, differentiation and dynamic evolution, have had profound effects on the contents of CAAD courses. An all-encompassing discussion of this paradigm is beyond the scope of this paper, but we may prospect that this argument will continue to inspire new theoretical content.

Considering the contents of individual CAAD courses, it seems that there is no limit. Computing, for modelling, simulation or communication, can be integrated with numerous topics. $A$ CAAD course can focus on teaching how to use a specific computer program, or basics of digital design can be taught. Nowadays, students begin to architectural education with significant computer experience (Pektas and Demirbas, 2007). Office programs, e-mail and Internet have already become common knowledge and the need for computer literacy courses have diminished. Thus, this type of information can be offered only to the needed and CAAD education can cover more sophisticated issues. Oxman (2006) discusses that as digital media become more complex and more demanding with respect to knowledge of multiple types of applications, a new generation of digital design specialists is emerging. She coins the term "digerati" 

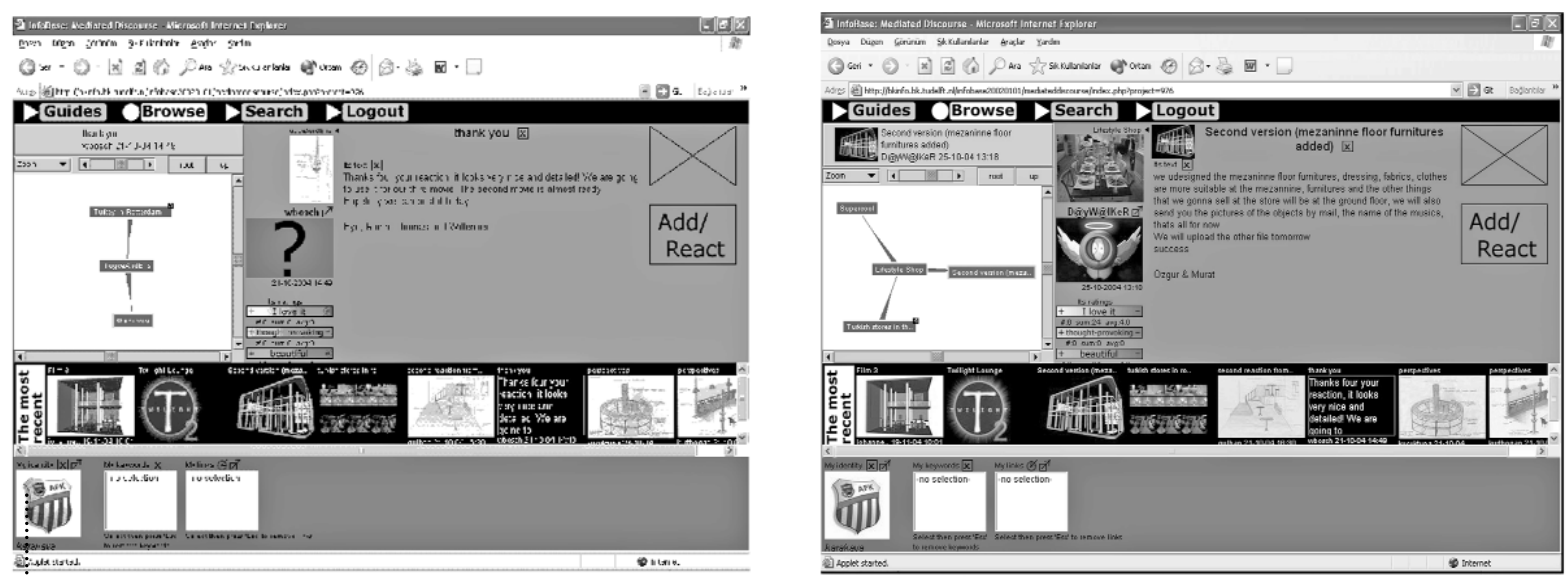

Fig 2. Web-based design studio as a rehearsal of professional collaboration between architects and interior designers. Snapshots from the communication in a virtual design studio conducted by Bilkent University, Turkey and Technical University of Delft, Netherlands during the Fall semester, 2004 (Moderator: F. Karakaya)

or digital literati corresponding to these new advanced digital systems designers. In order to educate "digerati," we suggest that since it is impossible -and also not necessary - to teach every CAAD package in the courses, only the core concepts should be introduced to students. Instead of burdening them with a mass of commands, students should be taught how to learn. The main aim of CAAD education in the digital age should be enabling students to understand the relevance of computing to their design process and to utilize it properly.

\section{METHODOLOGY AND MEDIUM}

Another important consideration about CAAD education is "how" it is delivered. In general, there are two main methods to teach CAAD in architectural schools: separate courses and the studio. There are also many hybrid applications and experimental practices. The studio is the main medium for the acquisition of design knowledge in architectural education. Therefore, it is assumed that it is the core and the other courses are complementary (Teymur, 1992: 34). Although some approaches claim that there is no need for CAAD courses since CAAD education should be a part of the design studio (Kalisperis and Pehlivanidou, 1998), separate CAAD courses are still the primary method of integrating computing in architectural curriculum. This situation is mostly due to the difficulties of fully dig- ital studios. Their costs are high and studio instructors have to devote considerable time and energy to the subject. Furthermore, problems arise on what should be the weight of computer technology in the studio and whether or not it is feasible pedagogically. Moreover, when computers are introduced to the studio without initial CAAD training, inexperienced students tend to focus on technical difficulties rather than design concepts and they may be limited by their computer skills. Thus, it seems appropriate that basics of digital design should be initially taught in separate courses. After the initiation, the design studios should reinforce this training (Marx, 2000).

Separate CAAD courses may suffer from crowded classes and a limited time frame which often make it difficult to cover a great deal of information. Furthermore, since students often learn CAAD techniques passively in preliminary courses, they may become unapt at applying these techniques in new situations (Tasli, 2001 a). In order to overcome these difficulties, we argue that CAAD education should be project-centric. Integrating CAAD with design projects enable students to explore the tools in the context in which they tend to be used. Moreover, in this way, computing is seen by the students as a part of the design process. Students are also more motivated to learn, because they are eager to produce a good project. Integration of CAAD and the design studio may not need to be revolutionary but small changes in educational programs, e.g. introduction of short design exercises 
that simultaneously develop both computing and design skills and knowledge, may facilitate for learning-by-doing.

Besides studios and separate CAAD courses, there is another category of courses which utilize the Internet and network technologies to realize collaborative design learning. The courses in this group have different names in the literature such as Web-based studio, virtual design studio, and online studio. Within their great variability, the only common feature of the different web-supported studios is that some of the participants are remotely located from others. There are many motivations underlying such courses. First of all, they expose students to foreign environments and ideas of wider scope than is possible in traditional studios. They also help to teach collaborative work, facilitate for distance education, and promote peer learning. AlQawasmi (2006) discusses that influences of virtual design studios have been so profound since early 1990s that they have totally transformed traditional studio culture and pedagogy which had largely remained unchanged until that period.

An important ingredient of CAAD education is the software utilized. Commercial software used in CAAD teaching can be grouped into two: draftingoriented software such as AutoCAD, ArchiCAD, CATIA, etc. and visualization-oriented software such as 3D Studio MAX, FormZ, Maya, Rhino, etc. Drafting-oriented software is widely used both in education and practice. Despite the developments in 3D modelling, 2D drawing still maintains its importance in CAAD education. In a recent survey of CAD instructors (Garcia et al., 2005), 2D drawing was considered as the most important aspect of CAD followed by dimensioning and layers, 3D modelling ranked fourth.

There is no doubt that 3D modelling and visualization software opened up new frontiers in students' imagination. Taking Gehry and Eisenman as their role-models, student designers are enthusiastic about experimenting with numerous complex forms within a limited time frame. The educational implications of these developments, however, should be carefully considered. On the one hand, increased number of design alternatives and the vision of a "non-standard" architecture are often viewed positively. On the other hand, it is observed

$-50$ that novice students fascinated by the representational capability of the tool are likely to ignore constructional and functional requirements of buildings in their projects. There is a growing amount of design instructors who complain about visually appealing but unbuildable student projects (Balfour, 2001).

Conventional CAAD software has already been integrated with architectural curricula, and it seems that the next step is parametric 3D modelling. Designing directly in 3D with intelligent objects has long been a dream of CAAD researchers (Tasli, 1999: 31-32). The elements in this type of modelling are "intelligent" in the sense that a wall is not merely two parallel lines but it "knows" that it is an architectural element which provides enclosure, bears loads and consists of openings for doors and windows. The 3D model becomes the source of all 2D drawings; sections and elevations can be automatically produced. Object-oriented programming enabled realization of these ideas in a great extent and toward the end of the 1990s most commercial CAD programs such as AutoCAD Architectural Desktop and AutoCAD Revit offered parametric 3D modelling (Autodesk, 2006). Some proponents of 3D modelling claimed that this technology will cause a revolutionary change in design processes of architects and classical plan-elevation-section will become obsolete (Novitski, 1998). However, this has not happened in reality not only due to the fact that changes in customary processes are difficult and incremental but also that those representations are insightful and useful abstractions of design ideas (Johnson, 2002). It seems that the new instance of 3D models have been embraced by architects not as a substitute of the conventional drawings but as a means to produce them consistently and efficiently. Whereas, in the educational practice, computer models are still viewed in traditional modelling terms as non-parametric, nonmutantable, static objects rather than object-oriented, dynamically simulated, virtual objects. Fortunately, developments in parametric 3D modelling software seem promising in order to overcome this problem (Tasli, 2001b). 


\section{STAFF AND MANAGEMENT}

Another important question regarding CAAD education is: "who" should be responsible for teaching CAAD? A decade ago, there was a lack of qualified full-time CAAD instructors in architectural schools. In 1997, a worldwide survey revealed that $55 \%$ of CAAD instructors were part-time (Qaqish and Hanna, 1997). Moreover, the studies consistently reported a tension between traditional and digital tools in the studios (Hanna and Barber, 2001). Due to the growing interest of academics in CAAD, a young generation of CAAD instructors who are both educators and researchers has emerged in the last decade, however, the reluctance in the studios seem to be persisted (Pektas and Erkip, 2006). Possible reasons for this reluctance are lack of proficiency of the instructors in computers (Erkip et al., 1997), focusing only on the "conceptual" phase of architectural design process and seeing the existing CAAD tools as merely drafting rather than design tools (Hanna and Barber, 2001), fearing that supporting CAAD in design education will lead to the loss of hand drawing skills in time (Shu, 2000), conservatism and caricaturizing the people who specialize in computers as "nerds" (Tweed, 2001). On the other hand, some instructors may be disinclined to use computers in education, since they perceive some shortcomings of the existing CAAD tools such as providing insufficient support at early design stages (Pektas and Erkip, 2006).

Integrating CAAD with design teaching necessitates collaboration of the faculty. Studio instructors, not necessarily being experts on the subject, should understand the potentials and limitations of the digital media. Team teaching may facilitate for this purpose. In this method, either a faculty member teaches both a CAAD class and a design studio at the same year level, or if this is not possible, CAAD instructors can contribute to studio critics just like environmental performance and construction tutors do. Both of these necessitate their being competent both in CAAD and design and devoting considerable effort to the task. Parallel exercises are another approach to integrate CAAD courses with the studio. The course sequence is an important consideration in that respect; introducing different lev- els of computing in the curriculum in step with the overall level of education may provide satisfactory results (Tasli, 2001a).

\section{ISSUES REGARDING DIFFERENT KNOWLEDGE LEVELS}

In order to present a systematic perspective to CAAD education, its different aspects should also be analyzed in sociological, ideological, epistemological and pedagogical levels. Sociological level corresponds to sociological definition of architectural education, its problems and contents. Although it has been known that individual differences of learners such as computer attitudes, learning styles/preferences, personality type and gender are influential in determining the success of efforts to integrate technology with education, most of the studies on CAAD (as well as the design institutions themselves) have focused merely on the technical aspects. Socio-cultural and behavioural issues of CAAD education have often been ignored (Pektas and Erkip, 2006). Hence, we believe that architectural education is urgently in need of researches on such aspects of CAAD.

Ideological level consists of relationships between architectural profession and its education. Architectural education, contributing to the reproduction of architectural labour force, is professionoriented unlike discipline-oriented science education (Teymur, 1994). Then, it is not surprising that there have always been disagreements between the practicing architects and the academia on the content and the methods of education. The different value systems of both parties manifest themselves in their approaches to CAAD teaching as well. Practitioners sometimes express disappointment about how students are trained for the profession and force schools to enhance their CAAD teaching (Novitski, 1999). While architectural practice tends to use CAAD in conventional terms, mostly for efficiency in production; in schools, approaches to CAAD span a wide range between hesitations toward utilization to advance uses of computers for augmenting architectural imagination. Unlike most architectural offices depend only on computerized drafting after the preliminary design stage; these 
two media tend to exist simultaneously in the schools.

Epistemological level is related to content and utilization of knowledge and its interdisciplinary aspects. Three main potentials of CAAD in this respect may be addressed, namely, systematization, different representations of design knowledge and collaboration (Tasli, 2001a). Architectural practice is often conducted through normative processes and intuition. Similarly, in architectural education, an architect is often portrayed as a "black box" that produces designs mysteriously. However, in order to work with a computer one has to be clear about the task, be it a process or a geometrical description. This may enable students to be aware of the steps or the procedures followed to complete a design. The possibility of different representations of design knowledge -in the form of visualizations, simulations, rules, or case studies- is another potential of CAAD in epistemological level. In the studio tradition, a studio instructor plays the role of the master who demonstrates how to design by a kind of thinking by doing which Schön called "reflection-inaction." (1985). In this practice, students' performance criteria for design are often based on the approval from the master. However, computers allow several representations of performance criteria (lighting, acoustics, structural strength, etc.) as well as the four-dimensional experience of building aesthetics, which can be easily accessed, or directly attached to the building model. In this way, students' own creativity can be more effectively merged with the theories of the discipline. Finally, establishing ways of sharing in design education promotes students' understanding of how different values exist simultaneously.

Pedagogical level involves learning theories, techniques and course design. Some of the pedagogical aspects of CAAD education are discussed in the previous sections. However, like its socio-cultural aspects, pedagogical aspects of CAAD are also rarely discussed in the literature. It seems that the rapid implementation of computers in design curricula has caught schools unprepared to develop new pedagogical methods adapted for a digital practice. Hence, systematic approaches and experimental research on the curriculum design and teaching methods are much needed.

\section{CONCLUSION}

In this paper, a framework for addressing most of the important aspects of CAAD education based on Teymur's system is suggested. Throughout the paper, it is emphasized that after many years of experimenting, computerized practices are no longer admired only for the sake of the tool, but their relevance to architecture education is questioned. Relations between digital design and architectural design theories, or prospective contents of a "digital design theory" are interesting inquiries toward a theoretical discourse of digital design. As educators and researchers, we may be inspired by this new agenda.

In schools, computers and visualization software are creating interesting opportunities for design experimentation. However, it is increasingly observed that, such experimentation is not wellconnected to building real-life projects. Parametric 3D modelling and dynamic simulation in virtual environments enable students to evaluate future performances of designs and developments in this area seem promising for bridging the gap between the fantasies of digital world and the materiality of the real-life. As costs of such systems decrease and their compatibility with modelling software increase, more educators will be able to utilize them and we may have a better understanding of how to teach students to design digitally.

CAAD education research has already established with its own knowledge base and research methods. However, most of the studies on the subject have traditionally focused on technical/empirical aspects of CAAD education (such as development of new tools and description of experimental CAAD courses). There are also relatively few theoretical studies basically dealing with the analysis and formal modelling of design processes and cognitive activities of designing such as the works of Cross (2000) and Lawson (1997). All of these approaches are valuable and produced significant results, but, the framework used in this paper revealed that the wide context of CAAD education has not been systematically analyzed, understood and exploited yet. Hence, we suggest that CAAD education community should focus more on the socio-cultural and pedagogical aspects of CAAD to 
better respond to the demands of the profession and the society at large. We hope that the framework proposed in this paper will facilitate for further studies.

\section{REFERENCES}

AL-QAWASMI, J. 2006, "Transformations in Design Education: The Paperless Studio and the Virtual Design Studio," Open House International, 31 (3), pp. 95-102.

AKIN, O. 1986, Psychology of Architectural Design, Pion, London, UK.

AUTODESK 2006, Autodesk Revit for AutoCAD Users, Available at:

http://images.autodesk.com/adsk/files/Revit_for_AutoCAD_U sers.pdf

BALFOUR, A. 2001, "Architecture and Electronic Media," Journal of Architectural Education, 54(4), pp. 268-271.

CROSS, N. 2000, Engineering Design Methods: Strategies for Product Design, John Wiley and Sons, Chichester, UK.

ERKIP, F., DEMIRKAN, H. and PULTAR, M. 1997, "Knowledge Acquisition for Design Education," Proceedings of the International Conference on Design and Technology Educational Research and Curriculum Development, Loughborough University, Loughborough, UK, pp. 126-132.

GARCIA, R. R., SANTOS, R. G., QUIROS, J. S., and PENIN, P. I. A. 2005, "Present State of CAD Teaching in Spanish Universities," Computers and Education, 44, pp. 201-215.

HANNA, R. and BARBER, T. 2001, "An Inquiry into Computers in Design: Attitudes before - Attitudes after," Design Studies, 13, pp. 255-281.

JOHNSON, S. 2002, "The Slow and Incremental "Revolution,"'" Journal of Architectural Education, 56(2), pp. 49-54.

KALISPERIS, L. N. and PEHLIVANIDOU, A. 1998, "Architectural Design Studio: Digital and Traditional," Computers in Design Studio Teaching: Proceedings of the EAAE-ECAADE Workshop, Leuven Dept. of Architecture, Leuven, Belgium, pp. 73-81.
LAWSON, B. 1997, How Designers Think, Architectural Press, London, UK.

LAWTON, D., GORDON, P., Ing, M., GIBBY, B., PRING, R. and MOORE, T. 1978, Theory and Practice of Curriculum Studies, Routledge \& Kegan Paul, London and New York.

MARX, J. 2000, "A Proposal for Alternative Methods for Teaching Digital Design," Automation in Construction, 9, pp. 19-35.

MIGAYROU F. and MENNAN, Z. 2003, Non Standard Architectures, Editions du Centre Pompidou, Paris.

MITCHELL, W. 2005, "Constructing Complexity," Proceedings of the Tenth International Conference on Computer Aided Design Futures, Vienna, Austria, pp. 41-50.

MITCHELL, W. 1994, "Three Paradigms for Computer Aided Design," Knowledge Based Computer Aided Architectural Design, G. Carrara and Y. Kalay (Eds.), Elsevier, Amsterdam, pp. 379-89.

NOVITSKI, B. J. 1999, "The Computer Education Received by Today's Architecture Students may not Provide them with the Skills Sought by Employers," Architectural Record, 187(4), pp. 39-42.

NOVITSKI, B. J. 1998, "An Architectural Awakening," Computer Graphics World, 21 (6), pp. 22-40.

OXMAN, R. 2006, "Theory and Design in the First Digital Age," Design Studies, 27, pp. 229-265.

PEKTAS, S. T. and DEMIRBAS, O. О. 2007, Computer Attitudes, Learning Styles and Computer Experiences of Interior Architecture Undergraduates, Unpublished Research Report, Bilkent University, Turkey.

PEKTAS, S. T. and ERKIP, F. 2006, "Attitudes of Design Students toward Computer Usage in Design," International Journal of Technology and Design Education, 16(1), pp. 7995.

PEKTAS, S. T. and PULTAR, M. 2006, "Modelling Detailed Information Flows in Building Design with the Parameterbased Design Structure Matrix," Design Studies, 27, pp. 99 122. 
QAQISH, R. and HANNA, R. A. 1997, "World-wide

Questionnaire Survey on the Use of Computers," Architectural Education, Architectural Design: Proceedings of the 15th ECAADE Conference, Available at:

http://info.tuwien.ac.at/ecaade/proc/qaqish/qaqish.htm

SAGUN, A., DEMIRKAN, H. and GOKTEPE, M., 2001, "A Framework for the Design Studio in Web-based Education," Journal of Art and Design Education, 20(3), pp. 332-342.

SALAMA, A. M. 2006, "Learning from the Environment: Evaluation Research and Experience Based Architectural Pedagogy," CEBE Transactions, 3(1), pp. 64-83.

SCHÖN, D. 1985, The Design Studio: An Exploration of its Traditions and Potentials, RIBA, London, UK.

SHU, E. H. A. 2000, "Touch versus Tech: Hand-drawn or Computer Rendered Techniques," Architectural Record, 188(2), pp. 170-173.

STEVENS, G. 1997, "Reflections of an Apostate CAD

Teacher," Journal of Architectural Education, 51 (1), pp. 78-80.

TASLI, S. 1999, Dynamic Simulation in Virtual Environments as an Evaluation Tool for Architectural Design, Unpublished Dissertation, Bilkent University, Turkey.

TASLI, S. 2001a, "Bridging the Gap between Theory and Practice in Architectural Education: The Case of CAAD Teaching," Re-integrating Theory and Design in Architectural Education: Proceedings of the 19th European Association for Architectural Education (EAAE) International Conference, EAAE, Leuven, Belgium, pp. 203-209.

TASLI, S. 2001b, "What does Computer Aided Design Offer for Producing Livable Buildings in the 21 st Century?" Proceedings of the Livable Environments and Architecture International Congress (LIVENARCH 2001), KTU, Trabzon, Turkey, pp. 278-282.

TEYMUR, N. 2001, 4x4 - Towards a Working Theory of Architectural Education, Presented at AEE 2001 Conference, Available at: http://cebe.cf.ac.uk/aee/pdfs/teymurl.pdf

TEYMUR, N. 1997, Bir Mimarlik Kuramina Dogru (Towards a Theory of Architecture), Mimarlik Egitimi Ve, TMMOB, Ankara, Turkey, pp. 5-43.
TEYMUR, N. 1994, "Initiation Myths and Curricular Fallacies," Beginnings in Architectural Education, ACSA/EAAE, NY, pp. 89-90.

TEYMUR, N. 1992, Architectural Education: Issues in Educational Practice and Policy, ?estion (sic) Press, London.

TWEED, C. 2001, "The Social Context of CAAD in Practice," Automation in Construction, 10, pp. 617-629.

UIA (The International Union of Architects) 2002, UIA and Architectural Education Reflections and Recommendations, Text adopted by the 2002 UIA Assembly, Berlin, Available at: www.via-architectes.org/image/PDF/Reflex_eng.pdf

Yapi Endustri Merkezi (YEM) 2006, Serbest Mimarlik Burolari Raporu 2005, Yapi Endustri Merkezi, Istanbul, Turkey.

\section{Author's Address:}

Sule Tasli Pektas

Bilkent University, Faculty of Art,

Design and Architecture, Ankara

TURKEY

tasli@bilkent.edu.tr 